\title{
Maximum Lightning Overvoltage Location and Reliability Indices in Power System with Combined Transmission Line
}

\author{
J. Sadeh, Member, IEEE, and Y. Damchi, Student Member, IEEE
}

\begin{abstract}
This paper, presents the effect of a cable line on the maximum overvoltage location along cable line and reliability indices in the power system with the combined transmission line (overhead line/cable line). Maximum overvoltage has a vital role in insulators design of high voltage cable. On the other hand, recently with the extension of power systems, maintaining the high degree service reliability is very important. High voltage cable insulations have undesirable effect on power system reliability. Therefore, in this study, the effect of cable line length and the number of span before a cable line are investigated on the amount and location of maximum overvoltage. Furthrmore, reliability indices are determined by changing length and age of a cable line in combined transmission line. Results show that cable line length does not change the maximum overvoltage location but has significantly effect on the amount of maximum overvoltage. Also, length and age of cable line effect on power system reliability indices considerably.
\end{abstract}

Index Terms-- Combined transmission line, overvoltage, power system reliability.

\section{NOMENCLATURE}

$\mathrm{V}_{+} \quad$ Positive mode of voltage;

$v_{\text {- }} \quad$ Negative mode of voltage;

$\mathrm{Z}_{\mathrm{C}} \quad$ Characteristic impedance of cable;

$\mathrm{Z}_{\mathrm{L}} \quad$ Characteristic impedance of overhead line;

$\mathrm{i}_{\text {arr }} \quad$ Surge arrester current;

$\Delta \mathrm{x}$ Maximum voltage location;

$\Delta \mathrm{t}$ Time difference between the maximum of the reflected wave and the maximum of the incoming wave;

$V$ Propagation wave velocity in cable line;

A Availability;

U Unavailability;

$T_{c} \quad$ Time period between consecutive tests;

$\lambda \quad$ Failure rate of component.

\section{INTRODUCTION}

$\mathrm{O}$ vervoltage caused by lightning must be considered when designing the cable insulation system [1] because it can be a major cause for underground cable failure. Surge arrester is used to decrease cable line faults [2]. On the other hand, the effect of cable length on transient behavior of cable line and consequently on the stressing condition of its insulation is very

J. Sadeh is with Electrical Engineering Department, Islamic Azad University, Gonabad Branch, Gonabad, Iran (e-mail: sadeh@um.ac.ir)

Y. Damchi is with Ferdowsi University of Mashhad, Mashhad, Iran (email: damchi@ieee.org) vital. The voltage peak in cable line becomes above the refracted wave from overhead line because of the successive reflection between cable ends, especially for short cable line. Therefore cable line length has a vital role in the insulation coordination [3], [4].

In recent years with the expansion of the power system and competing the electrical energy market, cause is to optimum designing power system and optimizing power system maintenance methods with decreasing unnecessary cost without affecting overall power system reliability.

Combined transmission line is one of the factors that affect on power system reliability indices, because cable lines are manufactured with high voltage insulations, while high voltage insulations are known as weak points in the power system in view of reliability. Therefore, many efforts have been done for increasing high voltage reliability insulation, e.g. improving insulation endurance and optimizing insulation system design [5].

Reliability analysis of the power system that contains combined line is very important because most faults on transmission lines are transient and these faults do not cause that overhead line be permanently out of service. Transient faults are typically caused by lightning activity, and they have a very short duration. Transient faults automatically clear by auto-reclose operation of the line circuit breakers. Automatic clearing operation time takes less than a second and clearing operation does not require human intervention. Whereas autoreclose operation can not clear cable insulation faults and also cable insulation does not restore like air insulated transmission line. Therefore, cable fault always causes that cable line completely be out of service [6]. Repairing damaged cable line takes several days or even some weeks [7].

The cable failure rate depends on several factors, such as voltage stress, age of cable line, insulation defects and design of cable [8]. Therefore, one of the factors that affect the combined transmission line reliability is age of cable, because of cable line failure rate increases by increasing cable line age [9].

In this paper, variations of the maximum overvoltage amount and location are analyzed by changing cable line length and number of spans before a cable line in the power system with a combined transmission line. Also, reliability analysis is performed for combined transmission line which the cable line is protected by surge arresters at both ends. 


\section{MAXIMUM OVERVOLTAGE LOCATION}

This study has been done on combined transmission line, which is shown in Fig. 1.

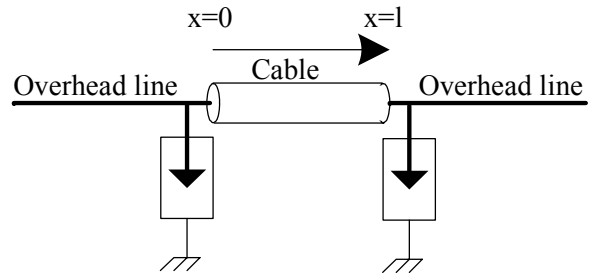

Fig. 1. Combined transmission line

The voltage at any point along the cable line is equal the sum of a positive and a negative propagating wave, i.e [1]:

$v(x, t)=v_{+}(x, t)+v_{-}(x, t)$

Another equation that related to surge arrester current in $\mathrm{x}=l$ is used to determine the positive and negative wave. Surge arrester current is calculated by (2) [1]:

$i_{\text {arr }}(t)=\frac{2 \times v_{+}(l, t)}{Z_{C}}-\frac{v(l, t)}{Z_{C}}-\frac{v(l, t)}{Z_{L}}$

Equation (2) is valid when the characteristic impedance of a cable and overhead line are assumed independent of the frequency.

With respect to equations (1) and (2), positive and negative wave are calculated by the following equations:

$v_{+}(l, t)=\left(\frac{Z_{C}}{2}\right) i_{a r r}(t)+\left(\frac{Z_{C}+Z_{L}}{2 Z_{L}}\right) v(l, t)$

$v_{-}(l, t)=v(l, t)-v_{+}(l, t)$

The maximum voltage location is determined using (4) [1]:

$$
\begin{aligned}
& \Delta x=V \times \frac{\Delta t}{2} \\
& \Delta t=t\left(v_{+}^{\max }\right)-t\left(v^{\max }\right)
\end{aligned}
$$

\section{RELIABILITY ANALYSIS}

In this study, reliability analysis has been performed using event tree method. Also, availability and unavailability have been used as reliability indices. For computing reliability indices, it is assumed that the failure of each component has exponential distribution function. With this assumption, unavailability indices are calculated using the following equation [10]:

$U=\frac{1}{T_{c}} \int_{0}^{T_{c}}\left(1-e^{-\lambda t}\right) d t=1-\frac{1}{\lambda T_{c}}\left(1-e^{-\lambda T_{c}}\right)$
If $\lambda T_{c}<<1$, (5) becomes as :

$U=\frac{\lambda T_{c}}{2}$

Availability index is calculated using the following equation:

$A=1-U \Rightarrow A=1-\frac{\lambda T_{c}}{2}$

In this study, to investigate the effect of cable line length and its age on the power system reliability indices, the (8) has been used in which $\lambda(t)$ is as instantaneous failure rate function of a cable line in respect to time $(\mathrm{t})$. Also, parameters of $k$ and $n$ are constant values that depend on the kind of cable [8].

$$
\lambda(t)=k t^{n} \quad \text { Failures / } 100 \text { mile / year }
$$

The event tree for Fig. 1 is shown in Fig. 2. In Fig. 2 overhead lines are shown by L1 and L2, surge arresters are shown by $\mathrm{B} 1$ and $\mathrm{B} 2$ and cable line is shown by $\mathrm{C}$.
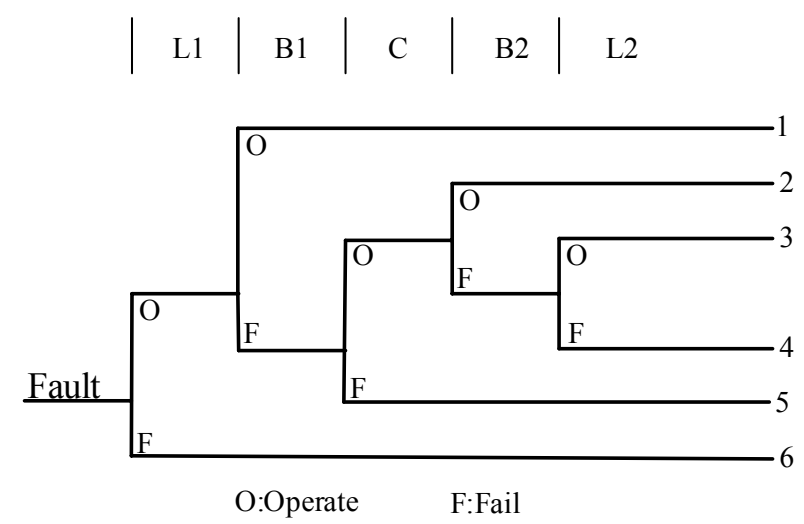

Fig. 2. Event tree combined transmission line

Event tree in Fig. 2 is explained as follows:

If the line L1 is not failed when an overvoltage occurred when surge arrester B1 operates suitable, route 1 will be constructed. In following, if line L1 does not become a failure against of overvoltage but surge arrester B1 does not have suitable operation and also, cable can tolerate overvoltage and surge arrester $\mathrm{B} 2$ has the suitable operation, route 2 will be constructed. Route 3 will be constructed if surge arrester B2 does not have the suitable operation and line L2 tolerates overvoltage. Now if line L2 is failed in contrast overvoltage, route 4 will be constructed. Route 5 will be constructed if overhead line L1 tolerates overvoltage but surge arrester B1 and cable line do not limit the overvoltage. Failure of a line L1 causes constructing route 6 .

In Fig. 2, routes (1), (2) and (3) are prosperity routes of a system and routes (4), (5) and (6) are failing routes of a system. Probability of these routes and reliability indices are calculated using (9). 


$$
\begin{aligned}
& P_{1}=A_{L 1} \times A_{B 1} \\
& P_{2}=A_{L 1} \times U_{B 1} \times A_{C} \times A_{B 2} \\
& P_{3}=A_{L 1} \times U_{B 1} \times A_{C} \times U_{B 2} \times A_{L 2} \\
& P_{4}=A_{L 1} \times U_{B 1} \times A_{C} \times U_{B 2} \times U_{L 2} \\
& P_{5}=A_{L 1} \times U_{B 1} \times U_{C} \\
& P_{6}=U_{L 1} \\
& A=P_{1}+P_{2}+P_{3} \\
& U=P_{4}+P_{5}+P_{6}
\end{aligned}
$$

\section{SIMULATION RESULTS}

In this study, power system in Fig. 3 is used to determine the amount and location of maximum overvoltage along the cable line. In this network, the length of the two the overhead lines in ends of cable are considered infinite with $Z_{L}=300 \Omega$, but for investigating the effect span numbers, four spans of an overhead line with length $300 \mathrm{~m}$ before a cable line are assumed separately. For cable line, Characteristic impedance of cable, the resistance and propagation velocity is considered $30 \Omega, 0.316 \Omega / \mathrm{km}$ and $174 \mathrm{~m} / \mu \mathrm{s}$, respectively. Also, lightning current is modeled as current, which increases to $30 \mathrm{kA}$ in $1 \mu \mathrm{s}$ and in infinite time deceases to half of this value. Protective level and per unit reference voltage, footing resistance and inductance of surge arrester are considered $636 \mathrm{kV}, 1 \Omega$ and 8 $\mu \mathrm{H}$. The characteristic of surge arrester is shown in Table I.

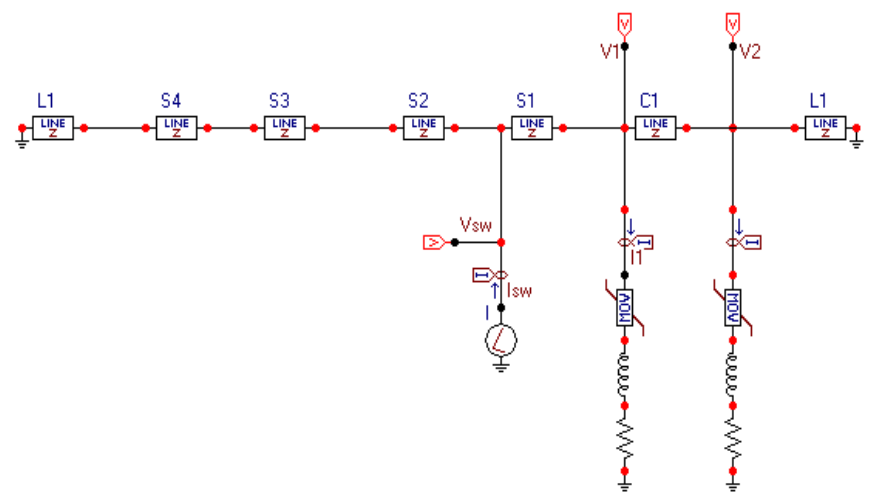

Fig. 3. Case study

TABLE I

SURGE ARRESTER CHARACTERISTIC

\begin{tabular}{c|c}
\hline Current $(\mathrm{A})$ & Voltage $(\mathrm{kV})$ \\
\hline \hline $10^{-4}$ & 276.98 \\
\hline $9.9996 \times 10^{-4}$ & 313.21 \\
\hline $9.9981 \times 10^{-3}$ & 332.74 \\
\hline $1.0002 \times 10^{-1}$ & 352.32 \\
\hline $9.9991 \times 10^{-1}$ & 377.72 \\
\hline $2.5 \times 10^{2}$ & 497 \\
\hline $1 \times 10^{3}$ & 533 \\
\hline $4.9998 \times 10^{4}$ & 595 \\
\hline $1 \times 10^{4}$ & 636 \\
\hline $2 \times 10^{4}$ & 702.20 \\
\hline
\end{tabular}

Failure rate of overhead line, cable line and surge arrester which presented in Table II is used to reliability analysis [11].

TABLE II

FAILURE RATES FOR COMPONENTS

\begin{tabular}{c|c}
\hline Component & Failure rate (Failures/ Year) \\
\hline \hline Overhead line & 0.01 \\
\hline Cable line & 0.001 \\
\hline Surge arrester & 0.001 \\
\hline
\end{tabular}

A. The Amount and Location of Maximum Overvoltage in Cable Line with Specific Length

To determine the amount and location of maximum overvoltage, cable length is assumed to be $2 \mathrm{~km}$ and footing resistance and footing inductance of surge arrester are neglected. Results are shown in Figs. 4 and 5.

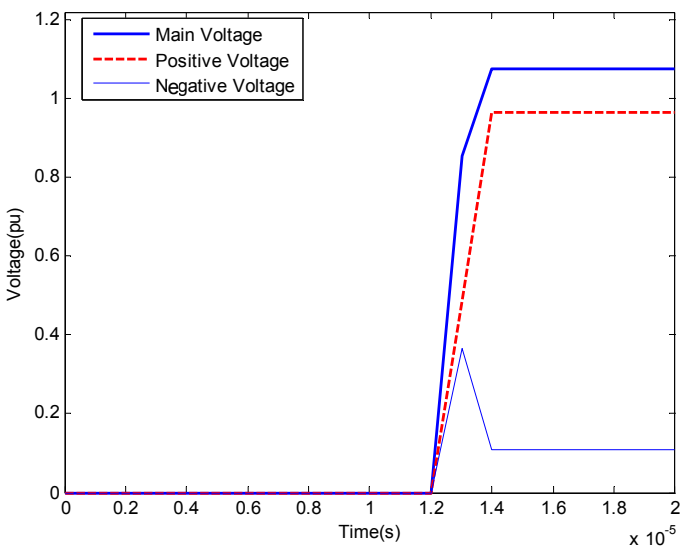

Fig. 4. Main, positive and negative voltage waves in the end of a cable line with length $2 \mathrm{~km}$

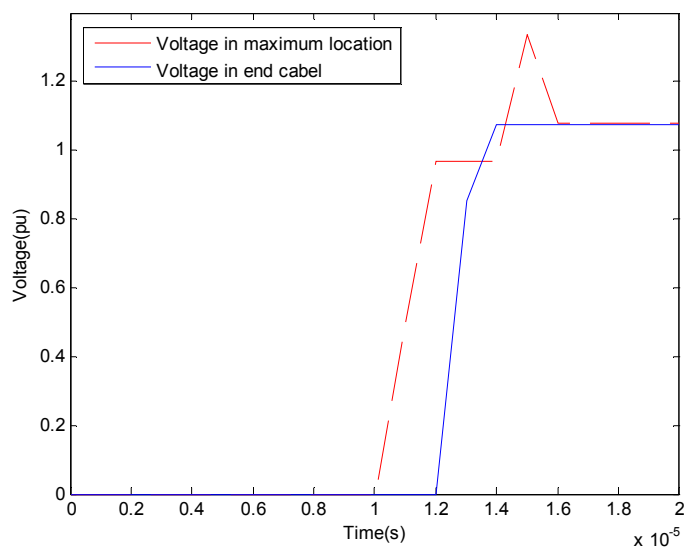

Fig. 5. Main voltage in real maximum overvoltage location and in end of a cable line with length $2 \mathrm{~km}$

Fig. 4 shows the positive and negative waves reach to their maximum at $17 \mu \mathrm{s}$ and $13 \mu \mathrm{s}$ in the end of cable $(\mathrm{x}=l)$, respectively. So, with respect to time difference between positive and negative waves and propagation wave velocity in cable line, the maximum overvoltage location occurs in $348 \mathrm{~m}$ from the end of cable. Fig. 5 demonstrates that maximum voltage in $348 \mathrm{~m}$ from the end of cable is equal to 1.3367 p.u. 
while this value is equal to 1.0758 p.u. in $\mathrm{x}=l$. This result shows that maximum overvoltage in the cable is $24.25 \%$ more than overvoltage in the end of a cable line.

\section{B. Effect of Cable Line Length on Amount and Location of} Maximum Overvoltage

To investigate the effect of cable line length on the location of maximum voltage, power system is simulated for cable line length $10 \mathrm{~km}$. Footing resistances and footing inductance of surge arrester are neglected. Result is shown in Fig. 6.

Fig. 6 shows positive, negative and main voltage waves in the end of cable with length $10 \mathrm{~km}$. Regarding to the Fig. 6 , maximum of positive and negative waves occurs at $63 \mu$ s and $59 \mu$ s. So, the time difference between positive and negative waves is $4 \mu \mathrm{s}$. In result, with respect to Figs. 4 and 6, the maximum overvoltage is occurred in the same time location as the previous conclusion while cable line length varies.

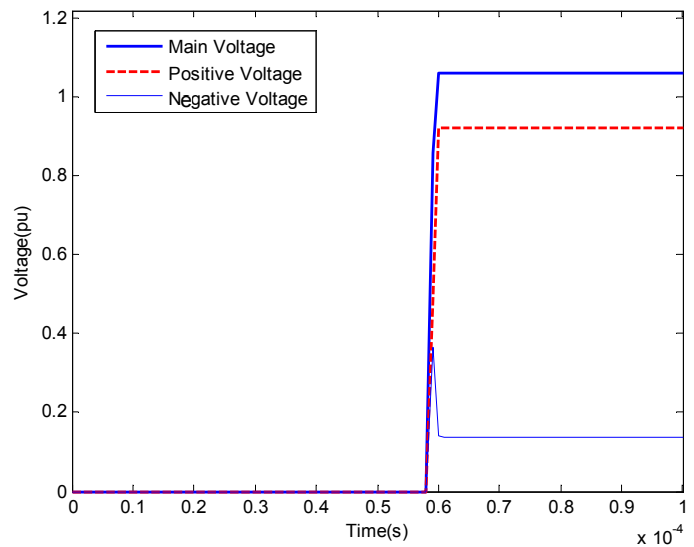

Fig. 6. Main, positive and negative voltage waves in the end of a cable line with length $10 \mathrm{~km}$

To analyze the effect of cable line length on the magnitude of maximum overvoltage, simulations have been perfumed considering deferent cable line lengths and footing resistance and inductance for surge arrester. Variations of the maximum overvoltage in the end of a cable line by increasing length of a cable line are shown in Fig. 7.

Regarding to this figure, it can be seen that the maximum overvoltage decreases by increasing length of the cable line. For example, maximum overvoltage decreases from 1.4008 p.u. to 1.0791 p.u. when cable line length increases from 0.5 $\mathrm{km}$ to $50 \mathrm{~km}$. With respect to Figs. 4 and 7, it can be concluded that considering footing resistance and inductance for surge arrester causes increasing voltage from $1.0758 \mathrm{pu}$ to $1.2956 \mathrm{pu}$. Therefore, optimum cable line length and exact model for surge arrester should be considered in designing of cable insulation because unsuitable design causes a insulation breakdown. Also, unsuitable design is a reason for increasing the failure rate of cable, which causes decreasing the reliability of the power system.

\section{Effect of Span Numbers before Cable Line on Amount of Maximum Overvoltage}

To investigate the effect of span numbers before cable line

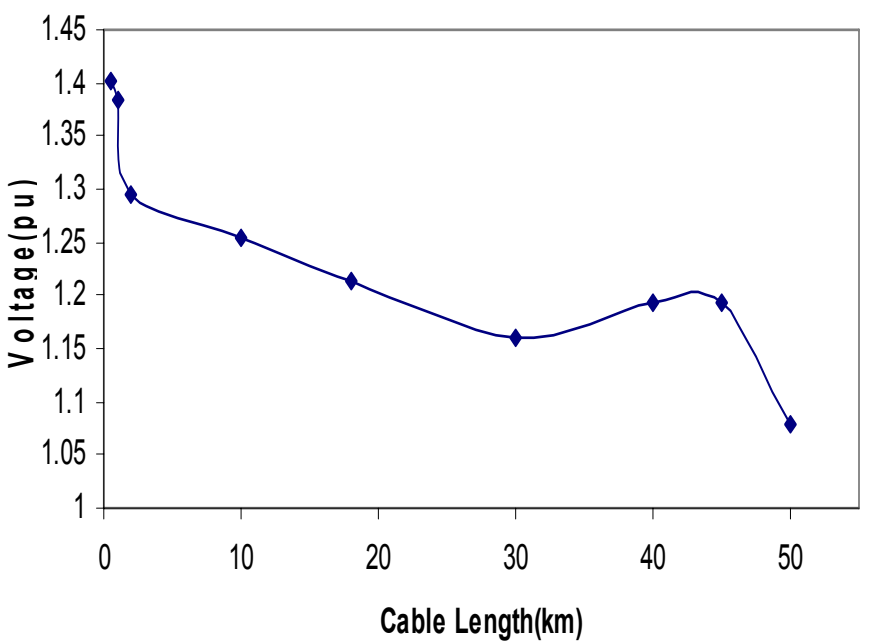

Fig. 7. Variations of voltage amount by increasing of a cable line length

length on the amount of maximum voltage, simulation has been performed considering two and four spans of overhead line before a cable line. Result presents in Fig. 8 in the real maximum overvoltage for cable line length $18 \mathrm{~km}$ without considering footing resistance and inductance for surge arrester.

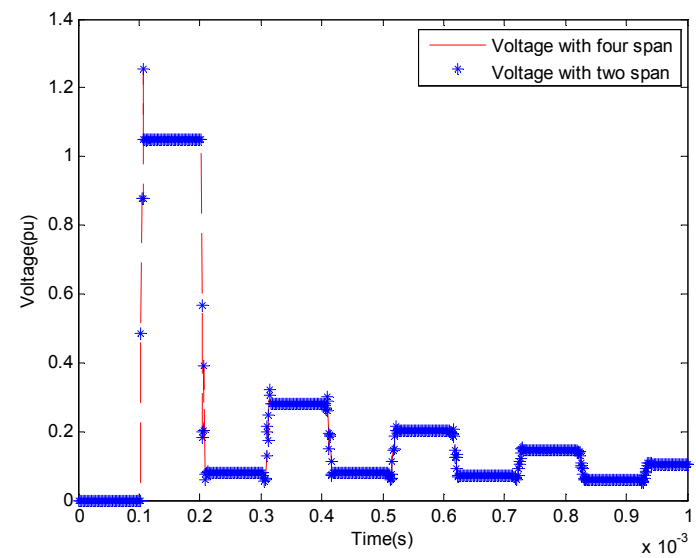

Fig. 8. Effect of span numbers before a cable line on voltage

Fig. 8 shows that voltage curve does not vary by changing the span numbers. Also, with comparison Figs. 5 and 8, it can be seen that overvoltage in cable line with length $2 \mathrm{Km}$ decreases from 1.3367 p.u. to 1.2558 p.u. in cable line with length $18(\mathrm{Km})$ in the real maximum overvoltage location. This result confirms decreasing overvoltage by increasing cable line length as the previous conclusion.

\section{Effect of Cable Line length on Reliability Indices}

To analyze the effect of cable length on combined line reliability, cross-linked polyethylene cable are investigated that for this cable, in Eq. 1, $n=1$ and $k=0.06$ (failures/100mileyear $^{2}$ ) [8]. Cable line failure rate can be calculated using Eq. 8 .

With the mentioned assumptions, Fig. 9 and Table III show the effect of cable line length on system reliability considering the time between consecutive tests is one year. 
TABLE III

VARIATIONS OF AVAILABILITY INDEX BY INCREASING CABLE LINE LENGTH

\begin{tabular}{c|c}
\hline Cable Line Length $(\mathrm{km})$ & Availability \\
\hline \hline 1 & 0.9950165 \\
\hline 10 & 0.9950157 \\
\hline 20 & 0.9950148 \\
\hline 30 & 0.9950138 \\
\hline 40 & 0.9950129 \\
\hline 50 & 0.9950120 \\
\hline
\end{tabular}

The presented result in Fig. 9 is shown that by increasing length of a cable line, system availability index decreases. Regarding to results of Table III, the amount of availability index for cable line with length $10 \mathrm{~km}$ decreases from 0.9950157 to 0.9950120 for cable line with length $50 \mathrm{~km}$.

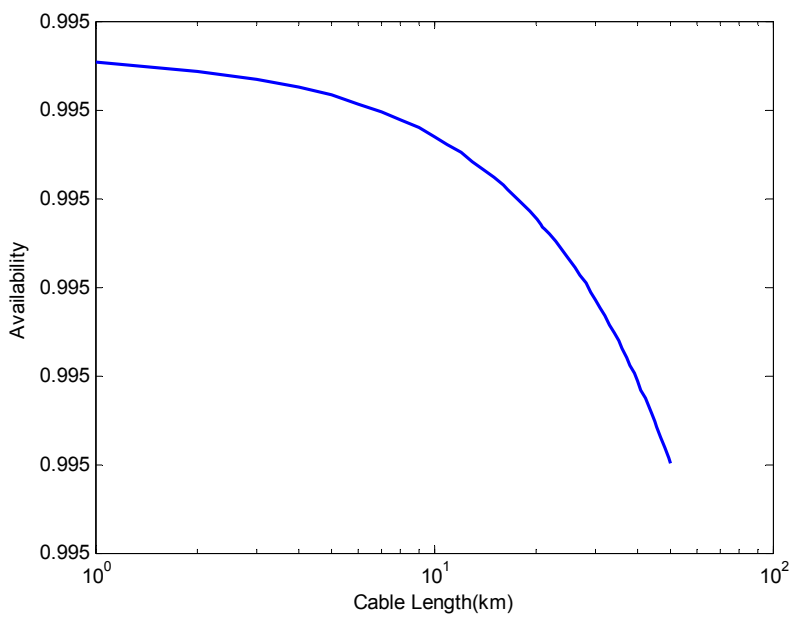

Fig. 9. Variations of availability index by increasing a cable line length

\section{E. Effect of Cable Line Age on Reliability Indices}

With respect to equation (8), age of cable line effects on a failure rate of cable line. So, simulation has been performed for cross-linked polyethylene cable with length $10(\mathrm{~km})$ to determine variation rate in reliability indices by increasing age of a cable line. Fig. 10 is shown the effect of cable line age on the power system reliability indices.

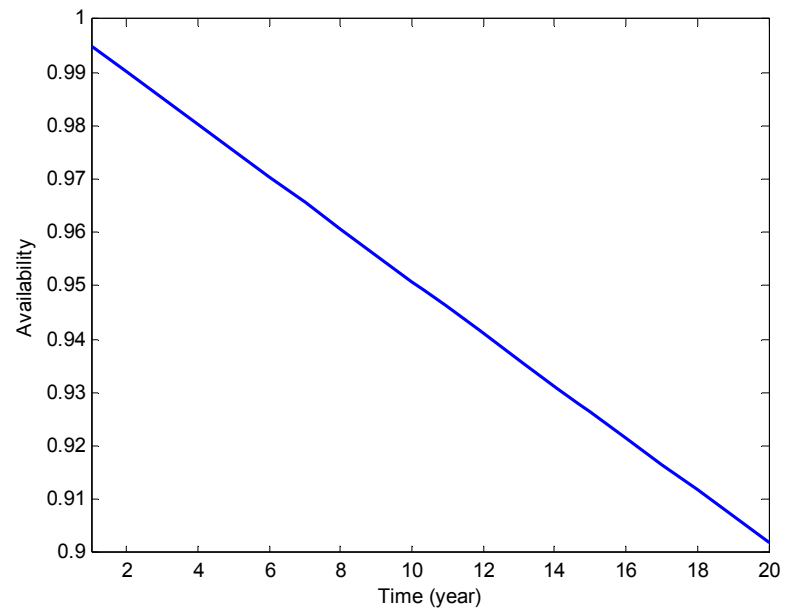

Fig. 10. Variations of availability index by increasing age of a cable line
Regarding to Fig. 10, power system availability decreases when age of cable line increases. For example, the amount of decreasing for ten years duration is $4.43 \%$. Therefore, decreasing of power system reliability with respect to age of a cable line is significant. Therefore, age of a cable has an effective role in design of a combined transmission line.

\section{CONCLUSIONS}

In this paper, the amount and location of maximum overvoltage along cable line have investigated by changing length of cable line and number of spans before a cable line in a combined transmission line. Also, reliability indices are calculated when age and length of cable varied. Results are shown that the amount of maximum overvoltage along cable line decreases by increasing of cable line length but the location of the maximum overvoltage does not vary by increasing of cable line length. Number of spans before a cable line does not affect on the amount and location of maximum overvoltage. Power system reliability decreases by increasing age and length of cable. Therefore, with respect to presented results, optimum cable line length and model for surge arrester should be exactly considered for determining of the maximum overvoltage amount and location because the maximum overvoltage strictly effects on the insulation coordination and consequently, on power system reliability indices.

\section{REFERENCES}

[1] M. T. Henriksen, B. Gustavsen, G. Balog and U. Baur, "Maximum Lightning Overvoltage Along a Cable Protected by Surge Arresters", IEEE Transactions on Power Delivery, Vol. 20, No. 2, pp. 859-866, April 2005.

[2] J.A. Martinez and F. Gonzalez-Molina, "Surge Protection of Underground Distribution Cables", IEEE Transactions on Power Delivery, Vol. 15, No. 2, pp. 756-763, April 2000.

[3] M. Marzinotto, "Relationship Between Statistical Distributions of Impinging and Stressing Overvoltages in Power Cable Lines", IEEE Lausanne Power Tech, pp. 1911 - 1916, July 2007.

[4] M. Marzinotto, C. Mazzetti and P. Schiaffino, "Statistical Approach to the Insulation Coordination of Medium and High Voltage Cable Lines", IEEE Power Tech, June 2005.

[5] E. Chiodo, D. Fabiani and G. Mazzanti, "Bayes Inference for Reliability of HV Insulation Systems in the Presence of Switching Voltage Surges Using a Weibull Stress-Strength Model", IEEE Bologna Power Tech Conference, June 2003.

[6] "Comparison of Reliability of a $400 \mathrm{kV}$ Underground Cable with an Overhead Lines for a $200 \mathrm{~km}$ long circuit", Transpower Report, Mar. 2005.

[7] "Effect of Short Cable Sections on Reliability of a $400 \mathrm{kV}$ Overhead Line", Transpower Report, Mar. 2005.

[8] W.F. Horton and A.N.S T. John, "The Failure Rate of Polyethylene Insulated Cable", IEEE/PES Transmission and Distribution Conference and Exposition, pp. 324-328, April 1979.

[9] Y. Zhou and R.E. Brown, "A Practical Method for Cable Failure Rate Modeling", IEEE/PES Transmission and Distribution Conference and Exposition, pp. 794-798, May 2006.

[10] R. Billinton and R.N. Allan, Reliability Evaluation of Power Systems, Boston Pitman Books, 1984.

[11] D. Zhu, R.P. Broadwater, Kwa-Sur Tam, R. Seguin and H Asgeirsson, "Impact of DG Placement on Reliability and Efficiency With Time-Varying Loads", IEEE Transactions on Power Delivery, Vol. 21, No. 1, pp.419-427, Feb. 2006 


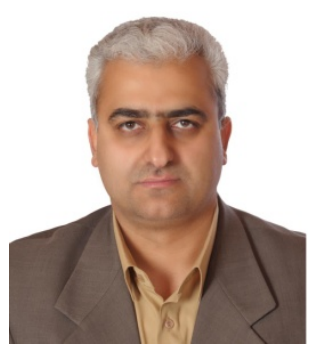

Javad Sadeh (M'08) was born in Mashhad, Iran in 1968. He received the B.Sc. and M.Sc. with honor both in Electrical Engineering from Ferdowsi University of Mashhad, Mashhad, Iran in 1990 and 1994, respectively and obtained his Ph.D. in Electrical Engineering from Sharif University of Technology, Tehran, Iran with the collaboration of the electrical engineering laboratory of the Institute National Polytechnique de Grenoble (INPG), France in 2001. He is currently an associate professor in the Department of Electrical Engineering at the Ferdowsi University of Mashhad, Mashhad, Iran. His research interests are power system protection, dynamics and operation.

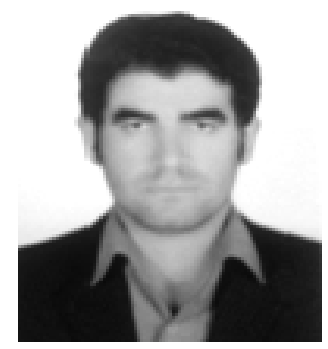

Yaser Damchi (S'10) was born in Babol, Iran in 1983. He received the B.Sc. degree in Electrical Power Engineering from Zanjan University, Zanjan, Iran, in 2006. $\mathrm{He}$ is currently a M.Sc. student in Electrical Power Engineering at Ferdowsi University of Mashhad, Mashhad, Iran. His research interests are power system protection and reliability analysis in power system. 